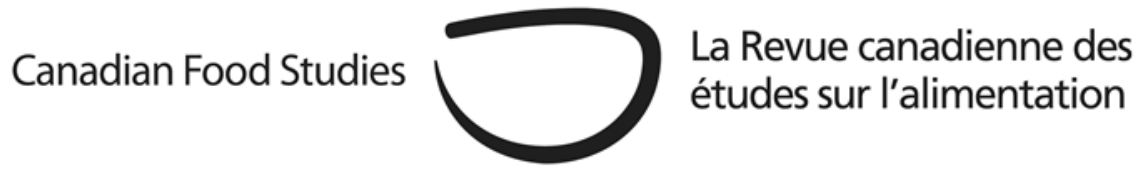

Original Research Article

\title{
A spatial analysis of population at risk of food insecurity using the voices from a Photovoice study
}

\author{
Mikiko Terashima ${ }^{a^{*}}$, Catherine Hart $^{\mathrm{b}}$, Patricia Williams ${ }^{\mathrm{b}}$ \\ ${ }^{a}$ Dalhousie University \\ ${ }^{\mathrm{b}}$ Mount Saint Vincent University
}

\begin{abstract}
It has been widely recognized that income is by far the most important factor affecting food insecurity for individuals and families. For those with low income and without a car, the local built environment they journey through to get to food likely adds to the challenges of accessing healthy and affordable food. Our study focused on understanding the challenges of obtaining food in the local built environment, using insights voiced by community members through a Photovoice study. We then used these insights to inform the assessment of populations without easy access to food outlets in four case communities with relatively high proportions of economically vulnerable individuals and families. Once a few of the relevant factors regarding barriers were incorporated in the GIS analysis, the estimated population outside of areas having access to supermarkets or any type of food outlets dramatically increased in both rural and urban communities. More detailed investigations of the unique built and social environmental conditions in both rural and urban communities are necessary, and the pairing of qualitative insights with a spatial analysis may be helpful.
\end{abstract}

Keywords: Mixed methods approach; food security; spatial analysis; Photovoice; Geographic Information Systems 


\section{Introduction}

A large volume of food security research has thus far uncovered multifaceted factors that influence how people obtain healthy and affordable food. Our understanding of food (in)security issues has been deepened by a number of methods - quantitatively by assessing the association with individual and socio-ecological factors (Breyer \& Voss-Andreae, 2013; Dillahunt \& Veinot, 2018; Guo, 2011; Huang et al., 2009), qualitatively through understanding lived experiences (Freedman, 2009; Loopstra \& Tarasuk, 2013; Meza et al., 2019; van der Velde et al., 2019), and spatially by characterizing presence, density, and proximity to food sources using geographic information systems (GIS) (Allard et al., 2017; Cochrane et al., 2019; Larsen et al., 2015; Zenk et al., 2005). Scholarship has widely recognized that individual economic circumstances, particularly low income, are the most significant contributors to food insecurity in Canada and globally (Loopstra \& Tarasuk, 2013; Nord et al., 2007). Various local built and social environmental characteristics have been investigated as other important factors (Glantz et al., 2005) that could exacerbate the challenges for low income individuals and households in acquiring healthy and affordable food, therefore putting them at a higher risk of food insecurity.

For those with low income and without a car, the local built environment they journey through to get to food likely adds to the challenges of accessing healthy and affordable food. However, accounts of these challenges are typically elicited qualitatively, and not often considered in research assessing the spatial accessibility of food outlets in communities (Caspi et al., 2012; Meener, 2019). Our study incorporated the insights of community members from four case communities on barriers to physical accessibility of food through a Photovoice study to better estimate populations potentially at risk of food insecurity.

\section{Background}

Food security has been broadly conceptualized by the Food and Agricultural Organization of the United Nations (1996) as "all people, at all times, hav[ing] physical and economic access to sufficient, safe and nutritious food that meets their dietary needs and food preferences for an active and healthy life" (in FAO, 2008, p.1). As such, an assessment of food insecurity often involves the question of access. In Canada, household food insecurity is measured as inadequate or insecure access to food specifically due to financial constraints (Dachner \& Tarasuk, 2018; Tarasuk et al., 2016). Access is a complex concept that includes the multitude of ways that individuals are either enabled to obtain goods and services or hindered from doing so. Penchansky and Thomas' (1981) theory of access includes five dimensions: 1) availability (if an adequate volume of goods/services are there for users to have them); 2) accessibility (locational relationships between goods/services and users); 3) accommodation (the ways in which services are provided, such as hours of operation); 4) affordability (relationships between prices of goods and individuals' ability to pay); and 5) acceptability (related to quality and characteristics of 
services). Saurman (2016) suggests that awareness (understanding of local contexts and needs in the population) be added as a sixth dimension.

Perhaps the most commonly studied dimensions within these concepts of access are accessibility and availability. A more sophisticated understanding of healthy and unhealthy food exposure, as well as affordability, has also emerged with a use of comprehensive store audit tools (Freedman, 2009; Horacek et al., 2018; Partington et al., 2015). Spatial accessibility research has also advanced in its conceptual understanding of access in recent years, moving beyond simply identifying low service areas — often described as 'food deserts' — which oversimplifies the possible mechanisms related to socioeconomic, cultural, and political contexts through which the ability of individuals and families is determined (LeClair \& Aksan, 2014; Macintyre, 2007; Widener 2018). This area of research has also recognized that people do not always obtain food in their particular residential environment, nor do they necessarily shop at the closest outlets (Hillier et al., 2011). People are exposed to different food environments around their places of work, school, and leisure (Chen \& Kwan, 2015). More recent research has therefore shifted from investigation of residential food environments using administrative area units to the evaluation of activity spaces by tracking individuals' routine movements (often with GPS) throughout the day to more accurately assess their exposure to different types of food environments and the influence this has on their food purchasing choices and behaviours (Widener et al., 2018). Scholarship is also beginning to assess the accessibility of food outlets by more clearly differentiating types of outlets such as convenience stores, farmers' markets, farm stands, and cooperatives (Jilcott Pitts et al., 2013; Van Hoesen et al., 2013), as well as community gardens, food banks, and community kitchens (Kirkpatrick \& Tarasuk, 2010), in their analyses. Further, 'transportation barriers' - including not having affordable transportation options such as public transit - have also been found to significantly influence how individuals (have to) make choices on where and what types of food they obtain (Farmer \& Minard, 2016).

Despite the relatively rapid deepening of our understanding of the complex ways individual and environmental factors influence the state of food security/insecurity, it is not yet clearly known how best to evaluate the mechanisms through which local environments influence access to healthy and affordable food for people living in lower income areas. Carter et al.'s (2014) critical review of the literature found that there has been a wide range of methodologies and scopes in research examining the influence of local environmental characteristics (including proximity to food outlets and types of places people live) on food insecurity, resulting in inconsistent findings as to whether local environments are indeed a risk factor.

The role of more physical aspects of access - such as proximity and density of food outlets - has particularly been subject to closer scrutiny (Shannon, 2016). For example, McInerney and colleagues (2016) found a positive association between food destination density in neighbourhoods and diet quality in Canadian adults. However, Kirkpatrick and Tarasuk's (2010) study of low-income families renting in low-income neighborhoods in Toronto showed that proximity to food retail or community food programs did not mitigate the risk of food insecurity, nor did neighbourhoods with poor geographic food access have particularly high rates 
of food insecurity. A more recent study by Allard and colleagues (2017) assessed the relationship between spatial access to food and household food security by incorporating multiple measures, including average distance to nearest food retailer, density of food outlets, and transportation mode access. They too found no consistent significant relationship between food security status and spatial access to food retailers between vulnerable and less vulnerable populations.

These studies demonstrate the importance of further untangling complex and compounding relationships between geographic and individual factors, particularly for people living in lower income areas (Breyer \& Voss-Andreae, 2013; Dillahunt \& Veinot, 2018; Ma et al., 2018). Our study is an attempt to partially fill this research gap through a spatial analysis that reflects on the qualitative insights of community members.

\section{Project context}

This study builds on a Photovoice study, which was part of a large-scale community food security research project conducted by the Food Action Research Centre (FoodARC), located at Mount Saint Vincent University in the Province of Nova Scotia, Canada. The Activating Change Together for Community Food Security (ACT for CFS) project has had enormous success in bringing a wide range of community and government organizations together to co-create and share knowledge of value with the local communities and province.

\section{Food ARC's ACT for CFS project}

The FoodARC has focused on research in partnership with communities tackling food security issues in Nova Scotia. FoodARC has played a pivotal role in influencing policy that seeks to improve Nova Scotians' access to affordable, healthy, safe, and culturally appropriate food that is distributed in socially, economically, and ecologically sustainable and just ways (FoodARC, 2019). For over a decade, FoodARC has produced a multitude of community-based study outcomes, including issues of formal and informal food production, costs of obtaining food, physical accessibility of food, accounts of experiences by vulnerable community members in accessing food, and nutrition education programs across the province.

Between 2010 and 2015, FoodARC conducted a large-scale multi-partnership project, Activating Change Together for Community Food Security (ACT for CFS), funded by the Social Sciences and Humanities Research Council, a national research funding agency in Canada. The project involved a partnership with over 70 organizations, including university, government, and community partners at local, provincial, and national levels, with representation from a range of disciplines and sectors. The purpose was to deepen the understanding of community food security (CFS) in the province from the perspectives of diverse interest groups. The project 
followed a Participatory Action Research (PAR) methodology using community-directed orientation to address questions that community participants identified themselves.

Part of the ACT for CFS project involved an investigation of poor food access in four selected communities. Three of the four case communities were rural (Eastern Shelburne County, Kings County Northeast, and Pictou County), while one was urban (Community of Spryfield). In general, these case communities were serviced by fewer food outlets and were relatively socioeconomically deprived compared with the provincial average (McNamee \& Rainham, 2014). They had lower household income, contained areas with a higher proportion of lowincome households than the provincial average, and the three rural case communities had lower employment rates than the provincial average (Table 1).

Table 1: Characteristics of the four case communities

\begin{tabular}{|c|c|c|c|c|c|}
\hline & $\begin{array}{l}\text { Nova } \\
\text { Scotia }\end{array}$ & $\begin{array}{l}\text { Eastern } \\
\text { Shelburne } \\
\text { County }\end{array}$ & $\begin{array}{c}\text { Kings } \\
\text { County } \\
\text { Northeast }\end{array}$ & $\begin{array}{l}\text { Pictou } \\
\text { County }\end{array}$ & Spryfield \\
\hline Median age & 43.7 & 49.7 & 44.1 & 45.1 & 40.3 \\
\hline$\%$ Single parents & $17.4 \%$ & $15.4 \%$ & $17.4 \%$ & $18 \%$ & $29.7 \%$ \\
\hline $\begin{array}{l}\text { Average household } \\
\text { income (after tax) }\end{array}$ & $\$ 55,883$ & $\$ 45,044$ & $\$ 52,468$ & $\$ 53,175$ & $\$ 48,112$ \\
\hline $\begin{array}{l}\% \text { living in the lowest } \\
25 \% \text { of median } \\
\text { household income DAs }\end{array}$ & $26.4 \%$ & $36.4 \%$ & $30.6 \%$ & $26.9 \%$ & $37.0 \%$ \\
\hline Employment rates & $56.8 \%$ & $46.7 \%$ & $53.9 \%$ & $53.3 \%$ & $58.7 \%$ \\
\hline Population size & 921,727 & 6,700 & 33,720 & 45,640 & 14,000 \\
\hline Geographic area size & $55,284 \mathrm{~km}^{2}$ & $1,964.6 \mathrm{~km}^{2}$ & $523.2 \mathrm{~km}^{2}$ & $2,889.9 \mathrm{~km}^{2}$ & $14.1 \mathrm{~km}^{2}$ \\
\hline
\end{tabular}

Source: Canadian Population Census 2011 (Statistics Canada, 2011)

Note: Median age and employment rates shown are average values of the Dissemination Areas included in the communities.

The ACT for CFS project also mapped the spatial coverage of existing food outlets in each community based on 10-minute walking and driving distances. The spatial analysis component of the project also identified sub-areas in each community with high socioeconomic deprivation scores and low food outlet access, revealing that many of the sub-areas had high risks of food insecurity (McNamee \& Rainham, 2014).

\section{Photovoice: Physical accessibility barriers in the four case communities}

A qualitative study of the case communities compiled narratives of the lived experiences of study participants in accessing (or having difficulties in accessing) food outlets through a series of 
Photovoice sessions. Photovoice is a type of participatory research method through which community participants use photography and stories about their photographs to represent issues they consider important (Nykiforuk et al., 2011). Twenty individuals from the four case communities participated in the Photovoice session, which generated rich information through personal accounts of challenges faced by the participants, revealing how multiple layers of barriers influence the way participants obtain food. The challenges voiced included considerations related to participants' personal experiences, such as not owning a car, having to carry many bags while walking with their children, and features of the environment itself, such as the distance to food providers, poor road conditions in inclement weather, and a lack of sidewalks.

The findings of the ACT for CFS project questioned the validity of using distance and density alone as spatial access factors without taking into account the factors involved in the journey to food outlets. Without taking these factors voiced in the Photovoice sessions into account, the maps of spatial access to food outlets produced likely underestimated the level of accessibility (i.e., geographic coverage of accessible areas) and food insecurity risks experienced by vulnerable groups. Incorporating these environmental factors highlighted by the participants could reveal a more "real" picture of spatial accessibility experienced by other vulnerable people. Moreover, the project team found that a further evaluation of spatial accessibility reflecting on the challenges pertaining to physical access to food identified from the Photovoice sessions could potentially better inform policy related to the physical environment in a more specific way.

\section{Objectives of this study}

The objectives of our study were two-fold: 1 . To more fully understand the challenges of physical access to food faced by case communities; and 2. To compare the assessments of the level of spatial accessibility to food with and without incorporating some of the key challenges related to the journey to obtain food that were highlighted by community members.

In order to achieve these objectives, we used the results from the Photovoice component of the ACT for CFS project, derived key barriers from the results of the Photovoice narratives, and incorporated some of these key barriers into the spatial analysis of accessibility by quantifying or spatializing them. We then assessed the differences in population coverage by food outlets for each of the case communities before and after incorporating these key barriers in the spatial analysis. Since our primary interest was community members who are often considered vulnerable and at risk of food insecurity, we focused on spatial accessibility from the perspective of those who do not own a car. 


\section{Methods}

This study took what Creswell (2003) called the "sequential exploratory" approach to a mixedmethods study. This approach utilizes both qualitative and quantitative data, whereby one type of data is collected and analyzed, and additional questions are then asked to build on these initial findings. We extracted some key narratives from the Photovoice sessions that were readily quantifiable across geographic space using available data, and accounted for these factors in calibrating the area coverage by food outlets. Therefore, the qualitative component (narratives from the Photovoice) precedes the quantitative component (assessment of the level of spatial accessibility), and the quantitative phase incorporates data informed by the qualitative, in-depth insights, in order to estimate the potential magnitude of challenges to food access at the population level. The details of this process are described below.

\section{Extracting "voices" from the Photovoice data}

Under the ACT for CFS project, a rigorous process of coding and participatory data analysis was undertaken to analyze the comprehensive data. The Photovoice component of the project was intended to elucidate challenges and opportunities with respect to the journey to obtain food. Photovoice is an increasingly employed PAR methodology (Nykiforuk et al., 2011) that involves participants as co-researchers who, through photography, "produce visual narratives of their experiences" (Nova Scotia Participatory Food Costing Project, 2013, p. 5). Group discussion sessions then took place in order for participants to speak about their photos. Sessions were guided by the PHOTO method (Latz, 2017, p.84), which frames five elements of the process for participants to consider:

1. P: Describe your photo;

2. H: What is happening in your photo?;

3. O: Why did you take a picture of this?;

4. T: What does this tell us about your life?; and

5. O: How can this picture provide opportunities for us to improve life?

A total of 20 individuals from the four case communities participated in the Photovoice study, which took place in November and December of 2013. The project team developed a clear and detailed manual for conducting a Photovoice study. Following the development of the manual, an extensive training workshop was conducted to ensure that participants were clear about the purpose and process of the activity and that they understood relevant ethical issues, as well as to practice taking photos. Participants then took photos to represent their everyday 
experiences, and they later came back for at least one of three facilitated group sessions to discuss and reflect on their photos and stories together. Comments from the Photovoice sessions were then transcribed and coded by theme.

The themes established from the Photovoice sessions - with a particular focus on the physical environmental barriers to accessing food-were then extracted. Some key example narratives were incorporated in the spatial analysis and are presented in the results section. Other factors related to barriers to accessing food that point to individuals' life circumstances prior to the journey to obtain food—-such as being short on cash and needing to take care of family members - were not included, as they are not directly related to the physical environment.

\section{Quantifying and spatializing the "voice"}

The Photovoice sessions yielded rich accounts of day-to-day challenges faced by the participants in each of the case communities with respect to the physical accessibility of food. Although the communities of the participants were identifiable, their comments were not considered as representative of a particular community in Nova Scotia. Rather, they largely pointed to physical elements common to most communities.

Three domains of physical barriers emerged from the Photovoice analysis:

Domain 1-Distance to large-scale, less expensive supermarkets as opposed to other, more expensive corner stores;

Domain 2-Road conditions pertaining to the journey on foot; and

Domain 3-Means of transportation, including public transit and taxi services.

Drawing on the photo narratives under these domains, we collected data that allowed us to depict these barriers using maps.

\section{Domain 1-Distance to large-scale, less expensive supermarkets}

For the first barrier identified above, we computed the service area coverage of supermarkets specifically versus all food outlets (excluding restaurants). The ACT for CFS project had already collected and geocoded the data for existing food outlets differentiated by store type. We computed the service area coverage by 10-, 20- and 30-minute walking distances to supermarkets specifically and to all food outlets. We focused only on walking distances as we are interested in population groups who are vulnerable to food insecurity due to their economic circumstances, and who tend not to own a vehicle. 


\section{Domain 2-Road conditions pertaining to the on-foot journey}

For the second domain, we mapped road steepness and lack of sidewalks, as highlighted in the Photovoice sessions. We calculated the difference in elevation between the ends of each road segment and determined that greater than a five-degree difference causes discomfort (and greater danger of falling when slippery in winter) for pedestrians (Kockelman et al., 2001; Meeder et al., 2017). The digital elevation model data were obtained from GeoNOVA, a geographic data service unit of the provincial government. Sidewalk data were only available (from the same source as data on bus stop location) for Spryfield and were not incorporated in the analyses of the other three communities. If there was no sidewalk on either side of the road, we considered that road to have barriers. After removing the road segments that were steep (in all four communities) and those that had no sidewalks (in Spryfield only), we recomputed the service area coverage.

\section{Domain 3-Means of transportation}

For the third domain, we computed the area covered by public transit (bus) and taxis by fee. Bus stop location data were available from the municipal open data source (https://cataloguehrm.opendata.arcgis.com). Areas that were not covered by a 10-minute walk to a bus stopabout $1 \mathrm{~km}$ distance based on the average person's walking speed (Daganzo, 2010)—were considered to have a barrier. For taxis, the geographic area coverage was evaluated based on three fare scales (one way) — $\$ 20, \$ 30$, and $\$ 50$ - using information provided by a taxi company showing fare-by-distance in Halifax as an example (https://www.numbeo.com/taxifare/in/Halifax). Among the four case communities, only Spryfield had regular public transit services, and its entire area was covered by a taxi fee of $\$ 20$. Therefore, public transit coverage was computed for Spryfield, and fare-based taxi coverage was computed for the other three communities (Eastern Shelburne County, Kings County Northeast, and Pictou). The spatial analysis of service coverage was conducted using the Network Analysis function of GIS software (ArcGIS 10.3, ESRI, Redland).

\section{Comparing the estimations of population coverage}

Finally, we estimated proportions of each community's population who may be at risk of not having access to food, based on the geographic coverage identified in the previous step. We used Canadian Census population data at the Dissemination Area (DA) level - the smallest census geographic administrative area for which population data are available - through the Dalhousie University Library database. Since residents were not uniformly spread across each census area, population covered by a given geographic range (by 10 minutes walking distance, for instance) 
was estimated using counts of buildings weighted by an average population size per building as determined for each DA; for the four case communities, this ranged between 1.7 and 2.6 people per building. The building point location data were available through GeoNOVA.

\section{Results}

The following section presents the results of the study, first describing the Photovoice results regarding the three domains of physical barriers to accessing food. Then, we present examples of maps for one of the case communities demonstrating population coverage before and after taking into account the spatial data representing the barriers related to each domain. Lastly, we describe how the levels of spatial accessibility (i.e., population coverage) for each case community changed when these barriers were considered for each domain.

\section{Domain 7. Distance to large-scale, less expensive supermarkets as opposed to} more expensive stores

Among the important insights voiced by participants from both rural and urban case communities was the distance to food outlets. This was unsurprising, as the challenges related to distance are consistent with the existing literature on food security (Larsen \& Gilliland, 2006; Sharkey, 2009; Slater et al., 2017; Smith et al., 2010; Wrigley, 2002). A photograph taken by one of the rural case community participants (Figure 1) illustrates the point that distance is always an underlying barrier that individuals mitigate through various coping strategies, such as asking friends to drive to the store, walking sometimes long distances, or taking a taxi. 
Figure 1: Photo by Cynthia Duncan "Distance Matters"

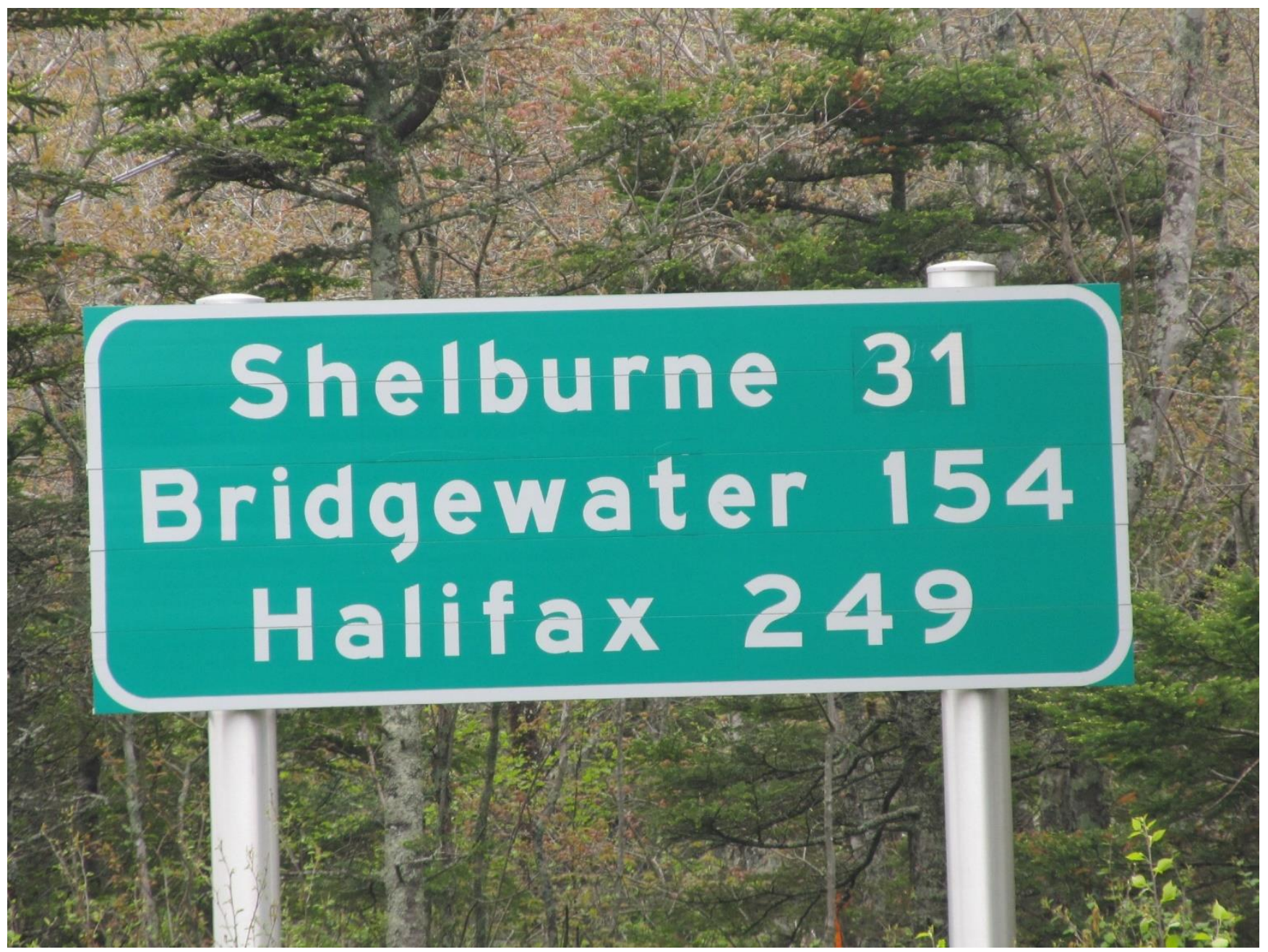

The problem, however, is often not distance to any stores, but rather distance to cheaper, higher quality food outlets. For instance, a Photovoice participant commented, "So it's just an example of the accessibility...but for me, if I wanted to buy food that is not in a convenience store that costs twice as much, I would have to drive 27 kilometers really" (Community Member A, Photovoice). This observation is echoed by another member in the same community: "Small corner stores and markets within walking distance carry items which are typically priced higher than similar items in a larger grocery store. Selection and variety are usually diminished as well, especially with regards to fresh meats and produce" (Community Member B, Photovoice). A leader of Northeastern Kings County's Kids Action Program also commented, outside of the Photovoice session, "It's quite a distance to get to a grocery store now. There are still a few other stores in the area, but they're smaller and more expensive. And there's no bus service, so people really need a vehicle or someone else to drive them around" (as cited in ACT for CFS, 2015, p. $61)$. 
Figure 2: Map 1: Area coverage by walking from all food outlets (left) and supermarkets specifically (right)

\section{Walk Distance From All Food Outlets}

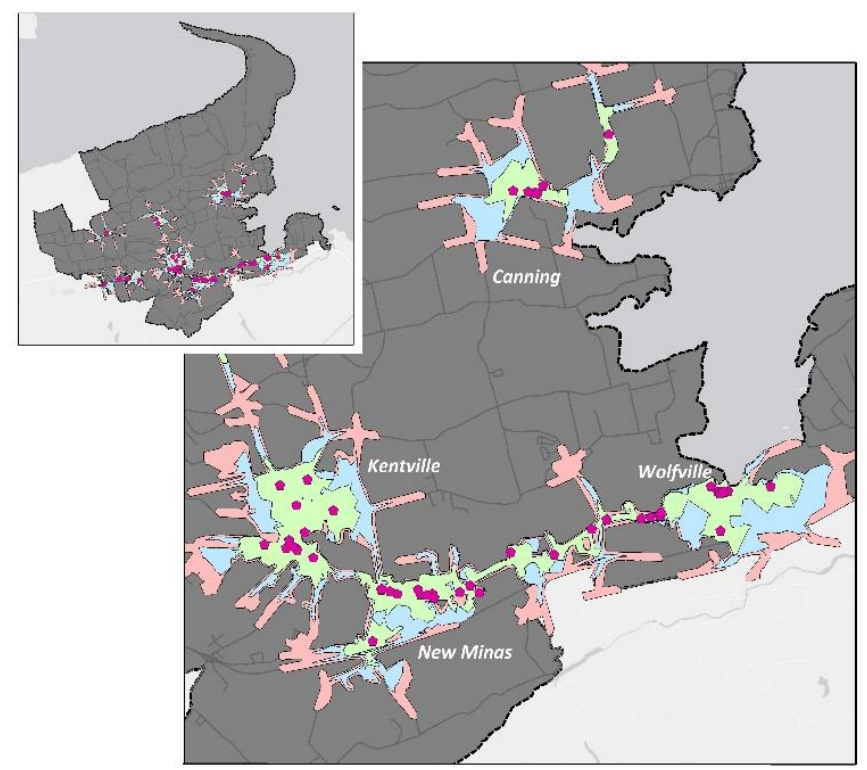

\section{Walk Distance From Supermarkets}

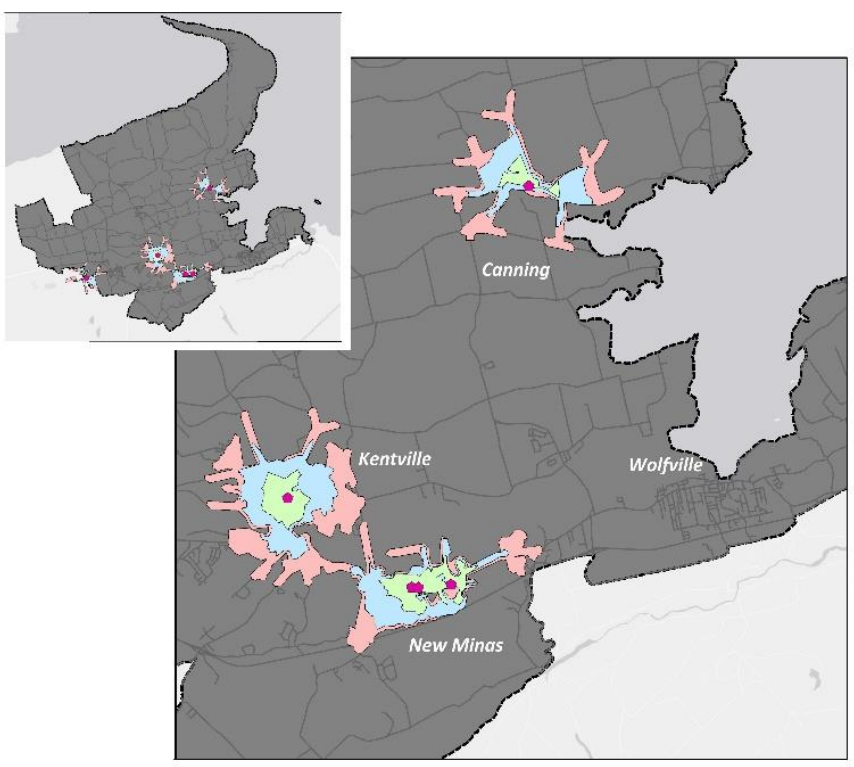

Legend

- Store Location

Roads

Kings County N.E.

10 Minute Walk From Outlet

20 Minute Walk From Outlet

30 Minute Walk From Outlet

Map 1 (Figure 2) shows comparisons between the spatial accessibility of all food outlets and large-scale supermarkets specifically in Kings County as an example. Table 2 shows that the proportions of the population outside of 10-, 20-, and 30-minute walking distance from all types of food outlets in the case communities reflect rurality, with Eastern Shelburne County and Pictou having some of the largest proportions of people outside of this range of coverage. Once spatial coverage was computed for supermarkets specifically, the proportions of people outside of this range further increase to nearly $80 \%$ or higher in all communities. However, the proportion of people outside the coverage of 10-minute walking distance in Spryfield doubles once supermarkets were specifically considered, becoming fairly equivalent to other more rural communities. In other words, only $10 \%$ to $20 \%$ of community members have access to supermarkets within 10-minute walking distance, regardless of rurality. Although we also presented coverage for 20- and 30-minute walking distance, it is unlikely that community members would regularly walk for longer periods of time carrying grocery bags. 
Table 2: Comparison of the proportions of the population living outside of 10-, 20-, and 30minute walking distance from all types of food outlets versus supermarkets specifically in case communities

\begin{tabular}{|c|c|c|c|c|c|c|c|}
\hline & \multirow[b]{2}{*}{$\begin{array}{l}\text { Total population } \\
\text { size }\end{array}$} & \multicolumn{3}{|c|}{$\begin{array}{l}\text { Population outside of coverage by } \\
\text { all food outlets }\end{array}$} & \multicolumn{3}{|c|}{$\begin{array}{l}\text { Population outside of coverage by } \\
\text { supermarkets specifically }\end{array}$} \\
\hline & & $\begin{array}{c}10- \\
\text { minute } \\
\text { walk }\end{array}$ & $\begin{array}{c}20- \\
\text { minute } \\
\text { walk }\end{array}$ & $\begin{array}{c}30- \\
\text { minute } \\
\text { walk }\end{array}$ & $\begin{array}{l}\text { 10-minute } \\
\text { walk }\end{array}$ & $\begin{array}{l}\text { 20-minute } \\
\text { walk }\end{array}$ & $\begin{array}{l}\text { 30-minute } \\
\text { walk }\end{array}$ \\
\hline $\begin{array}{l}\text { Eastern } \\
\text { Shelburne } \\
\text { County }\end{array}$ & 6,700 & $73.6 \%$ & $65.2 \%$ & $59.6 \%$ & $\begin{array}{r}95.6 \% \\
(+22.0 \%)\end{array}$ & $\begin{array}{r}84.4 \% \\
(+19.2 \%)\end{array}$ & $\begin{array}{r}80.2 \% \\
(+20.6 \%)\end{array}$ \\
\hline $\begin{array}{l}\text { Kings } \\
\text { County } \\
\text { Northeast }\end{array}$ & 33,720 & $60.2 \%$ & $39.3 \%$ & $28.6 \%$ & $\begin{array}{r}91.6 \% \\
(+31.3 \%)\end{array}$ & $\begin{array}{r}74.3 \% \\
(+35.0 \%)\end{array}$ & $\begin{array}{r}61.3 \% \\
(32.7 \%)\end{array}$ \\
\hline Pictou & 45,640 & $69.9 \%$ & $51.8 \%$ & $43.8 \%$ & $\begin{array}{r}88.1 \% \\
(+18.2 \%)\end{array}$ & $\begin{array}{r}70.2 \% \\
(+18.4 \%)\end{array}$ & $\begin{array}{r}60.6 \% \\
(+16.8 \%)\end{array}$ \\
\hline Spryfield & 14,000 & $53.0 \%$ & $5.8 \%$ & $0.6 \%$ & $\begin{array}{r}81.5 \% \\
(+28.6 \%)\end{array}$ & $\begin{array}{r}52.2 \% \\
(+46.4 \%)\end{array}$ & $\begin{array}{r}13.0 \% \\
(+12.4 \%)\end{array}$ \\
\hline
\end{tabular}

Domain 2. Road conditions for the on-foot journey

The Photovoice participants also revealed that walking for even a short distance to a store is often not a simple matter. The amount of food an individual can carry while walking or biking is influenced by topographic characteristics and maintenance conditions of the roads. The same distance is not necessarily equal in terms of how easy or difficult it is to travel. For instance, if the return journey to a store involves steep hills, it exacerbates the difficulty of carrying groceries, even for a short distance. One community member explained, "I walked... When I lived in [...], I had no source of transportation. I'd walk my kids back and forth to the daycare and the grocery store, and lug like six bags up the hill and home" (Community member E, Photovoice). 
Figure 3: Map 2: Hilly roads in Kings County Northeast

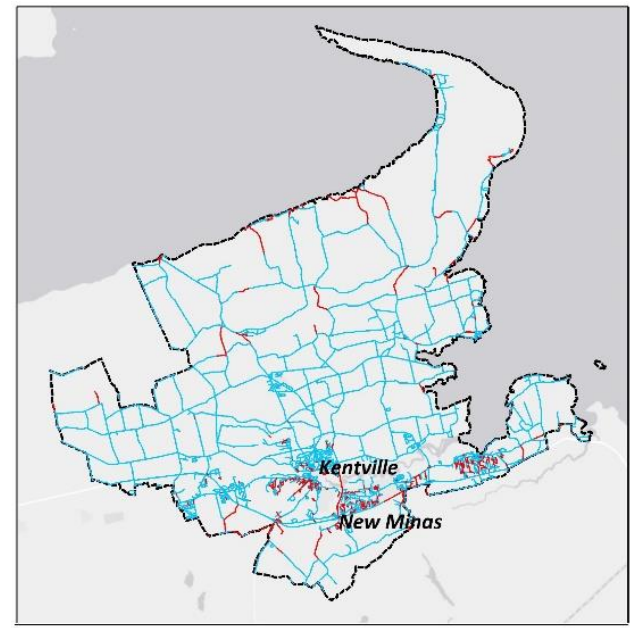

\section{Legend}

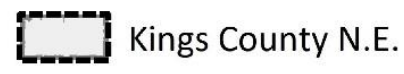

\section{Average Slope of Road}

Less than 5 Degrees

- Greater than 5 Degrees

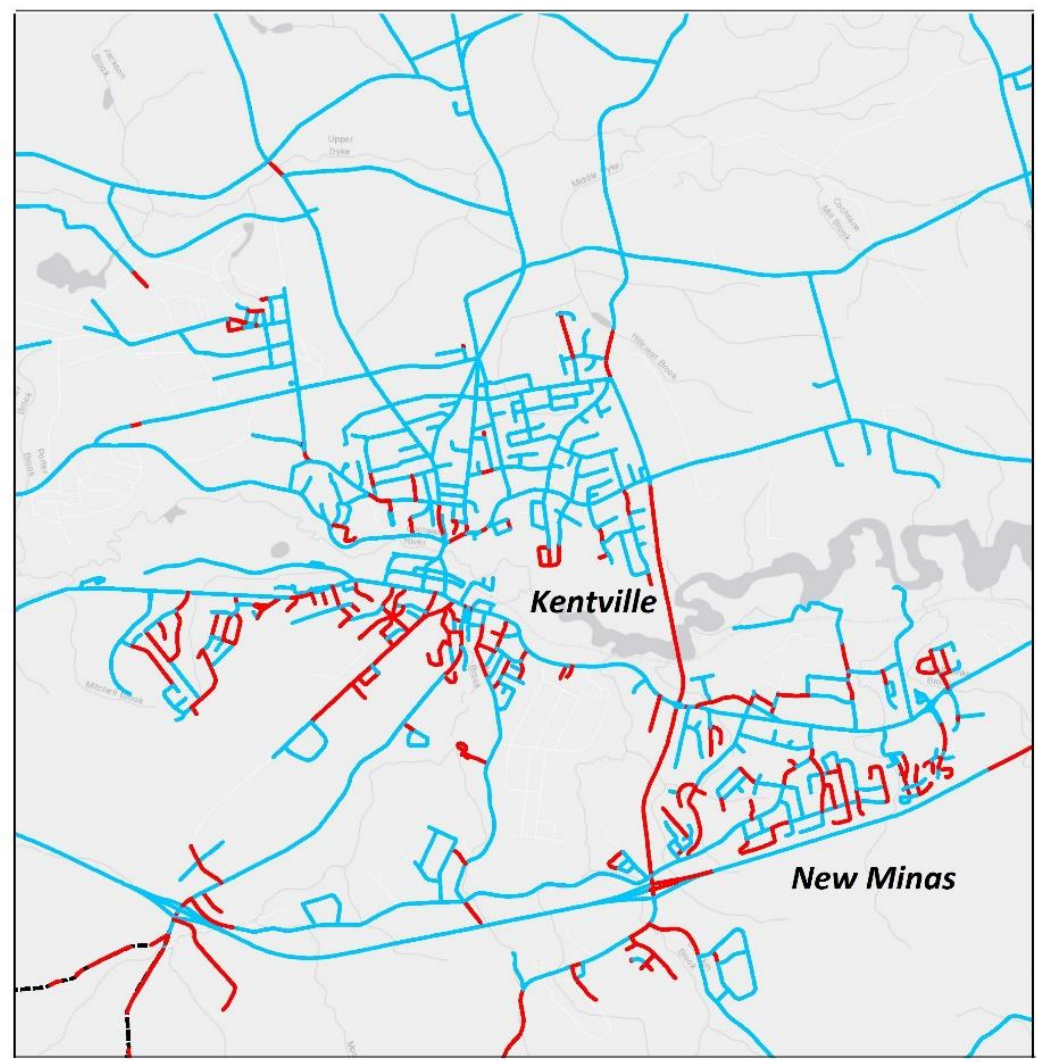

Map 2 (Figure 3) shows the distribution of roads classified based on slope (greater or less than five degrees) in Kings County. In Kings County, hilly roads are concentrated in relatively more populated areas surrounding its two largest towns, Kentville and New Minas. Sidewalks are critical built environmental features for protecting pedestrians and making them feel safe while walking. Since many food outlets are often located on main streets, sidewalks may be available around them. However, residential streets are often not equipped with sidewalks. Since rural jurisdictions do not routinely collect sidewalk data, we were unable to analyze the levels of sidewalk coverage in rural case communities. Of the four case communities, sidewalk data were therefore only available for Spryfield. As seen in Map 3 (Figure 4), a considerable number of road segments do not have sidewalks, including some of the main streets where automobile traffic is heavy, and the speed limit is high. 
Figure 4: Map 3: Roads with and without sidewalks (Spryfield)

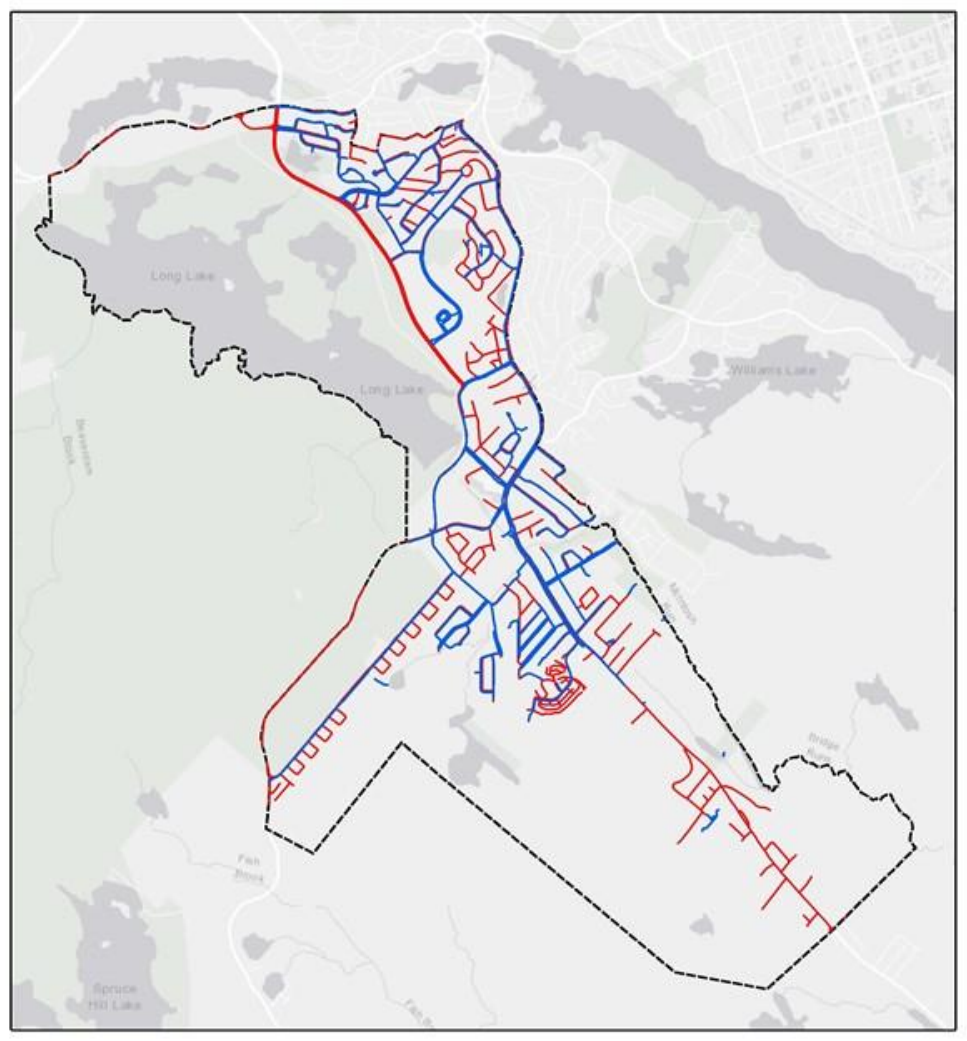

\section{Legend}

_ Roads with Sidewalks

Roads without Sidewalks

[-- Spryfield

Table 3: Comparisons of the proportion of population who cannot reach food outlets without walking on steep roads (all communities) or roads without sidewalks (Spryfield)

\begin{tabular}{|c|c|c|c|c|c|c|c|}
\hline & \multirow[b]{2}{*}{$\begin{array}{l}\text { Total population } \\
\text { size }\end{array}$} & \multicolumn{3}{|c|}{$\begin{array}{l}\text { Population outside of coverage by } \\
\text { supermarkets }\end{array}$} & \multicolumn{3}{|c|}{$\begin{array}{c}\text { Population outside coverage requiring } \\
\text { trips on roads with greater than 5- } \\
\text { degree slopes }\end{array}$} \\
\hline & & $\begin{array}{c}\text { Outside } \\
10- \\
\text { minute } \\
\text { range }\end{array}$ & $\begin{array}{l}\text { Outside } \\
20- \\
\text { minute } \\
\text { range }\end{array}$ & $\begin{array}{c}\text { Outside } \\
30- \\
\text { minute } \\
\text { range }\end{array}$ & $\begin{array}{c}\text { Outside } \\
10- \\
\text { minute } \\
\text { range }\end{array}$ & $\begin{array}{l}\text { Outside } \\
\text { 20-minute } \\
\text { range }\end{array}$ & $\begin{array}{l}\text { Outside } 30- \\
\text { minute } \\
\text { range }\end{array}$ \\
\hline $\begin{array}{l}\text { Shelburne } \\
\text { County East }\end{array}$ & 6,700 & $95.6 \%$ & $84.4 \%$ & $80.2 \%$ & $\begin{array}{l}95.7 \% \\
(+0 \%)\end{array}$ & $\begin{array}{r}85.5 \% \\
(+1.1 \%)\end{array}$ & $\begin{array}{r}80.3 \% \\
(+0.1 \%)\end{array}$ \\
\hline
\end{tabular}




\begin{tabular}{|c|c|c|c|c|c|c|c|}
\hline Kings County & 33,720 & $91.6 \%$ & $74.3 \%$ & $61.3 \%$ & $94.5 \%$ & $87.3 \%$ & $80.1 \%$ \\
\hline Northeast & & & & & $(+2.9 \%)$ & $(+13.0 \%)$ & $(+18.8 \%)$ \\
\hline \multirow[t]{2}{*}{ Pictou } & 45,640 & $88.1 \%$ & $70.2 \%$ & $60.6 \%$ & $93.0 \%$ & $81.2 \%$ & $74.3 \%$ \\
\hline & & & & & $(+4.9 \%)$ & $(+11.0 \%)$ & $(+13.7 \%)$ \\
\hline \multirow[t]{7}{*}{ Spryfield } & 14,000 & $81.5 \%$ & $52.2 \%$ & $13.0 \%$ & $90.8 \%$ & $88.3 \%$ & $86.7 \%$ \\
\hline & & & & & $(+9.3 \%)$ & $(+36.2 \%)$ & $(+73.7 \%)$ \\
\hline & & & & & \multirow{4}{*}{\multicolumn{3}{|c|}{$\begin{array}{r}\text { Population who has to walk on a road } \\
\text { without sidewalks or that must traverse } \\
\text { greater than 5-degree slopes to get to } \\
\text { food }\end{array}$}} \\
\hline & & & & & & & \\
\hline & & & & & & & \\
\hline & & & & & & & \\
\hline & & & & & $94.8 \%$ & $88.4 \%$ & $88.2 \%$ \\
\hline
\end{tabular}

Once the slope of roads is taken into consideration, the population outside of supermarket coverage further increases in all of the four case communities. For Spryfield, we were also able to identify the proportion of residents who either have to walk on a street without sidewalks or have to walk on a road greater than 5 degrees in slope (Table 3). It is important to note that, even if sidewalks are present, many of them are not well maintained (ACT for CFS, 2015; Figure 5), which often presents difficulties related to reduced safety for those sharing the road with motor vehicles. As one participant pointed out, "One of the many crumbling sidewalks in [...]... It is a constant obstacle course maneuvering up and down street by foot. I cannot even imagine trying to do so with a mobility issue such as needing a cane, crutches, or a wheelchair" (Community Member, Photovoice). While we were unable to include the barriers related to the dilapidated conditions of roads and sidewalks in this analysis, it only worsens the level of spatial access rather than improving it. 
Figure 5: Photo by Shelby Caldwell

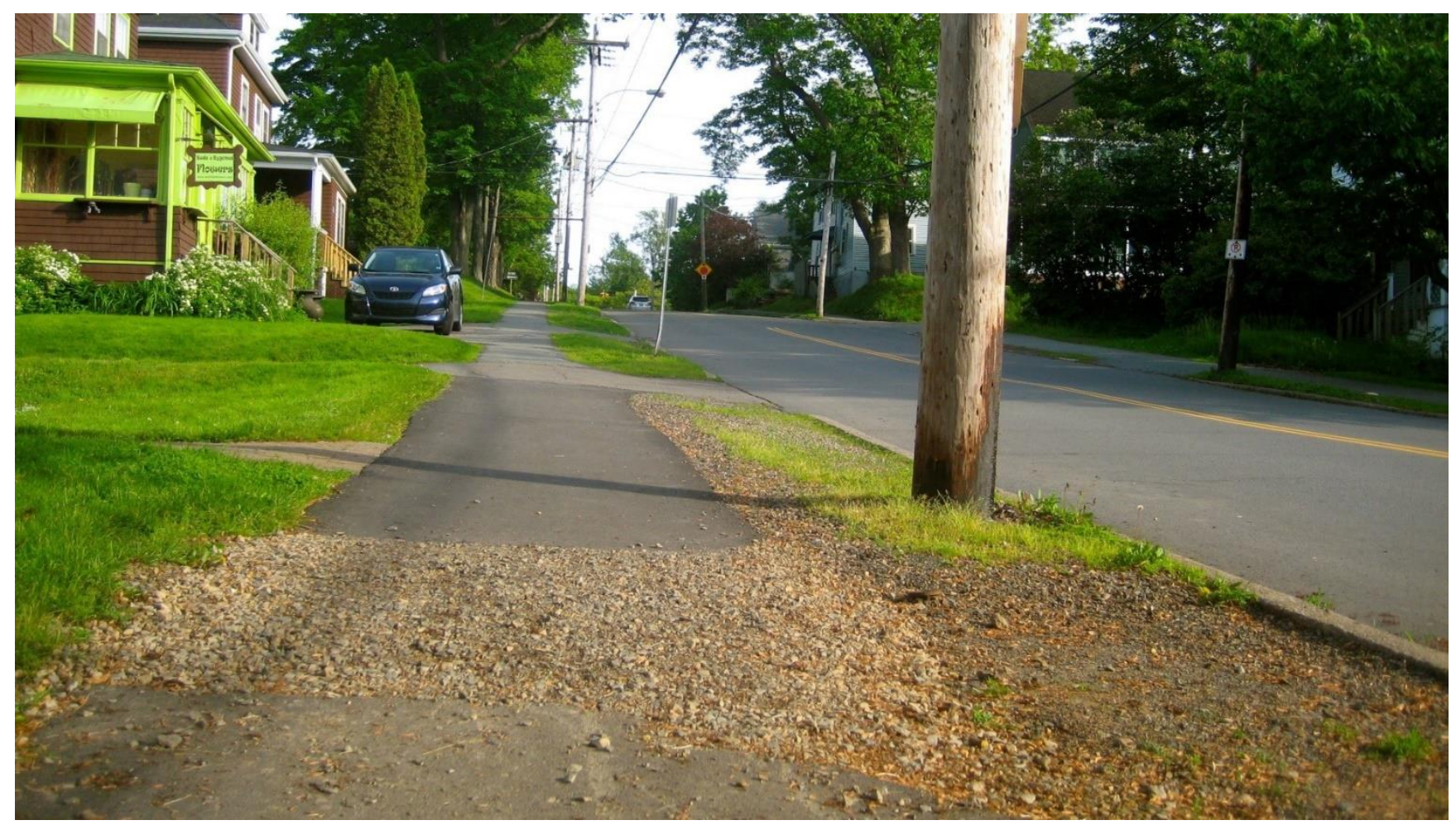

Domain 2. Challenges with means of transportation, including public transit and taxi services.

Accessibility barriers due to distance could be alleviated substantially with residents' improved access to a public transit system. For instance, although high proportions of the residents in Spryfield are outside of 10-minute walking distance to food outlets (53\% for all food outlets and $81.5 \%$ for supermarkets), all residents live within a 10-minute walk of at least one bus stop. However, there are virtually no public transit services in Pictou, Kings County Northeast, and Eastern Shelburne Counties.

Many participants in the Photovoice sessions discussed the difficulties of affording a car, the cost of taxis, and having limited or no public transit service (ACT for CFS, 2015). A person who does not own a car needs to take a taxi, get a ride with a friend or family member, or access one of the limited (and not well-known or advertised) community transportation services. Taking a taxi is unaffordable for some and reduces money available to spend on food for many people living on low incomes. Some participants elaborated on costs associated with transportation and how this influences their decisions. One community member said, "I try to budget in the fresh fruits and vegetables and I go...the cab was 25 dollars off the mountain to [...] and that was a 
certain point in [...], if you go any further then it's more uh so it was 25 uh dollars there and then if I wanted to go to [...] farm market because I really loved going to [...] farm market to get my stuff it was an extra thirteen dollars because it was an out of the way trip" (Community Member C, Photovoice). Another participant added, "I spend 250 dollars just on transportation alone in a month just to get my groceries and stuff to and from home and I have to do it a lot now...I find it hard breathe up and down the hill as things progress more and more" (Community member D, Photovoice). According to a third community member, "Well if you live in the municipality as opposed to the town and you want to get to [...] to get grocery shopping you're looking at $\$ 25$, \$20-\$25-\$30 [of taxi rides]" (Community member E, Photovoice).

Figure 6: Map 4: Areas covered by $\$ 20, \$ 30$ and $\$ 50$ one-way fares from all food outlets (left) and supermarkets specifically (right)

Taxi Ride Distances From All Food Outlets

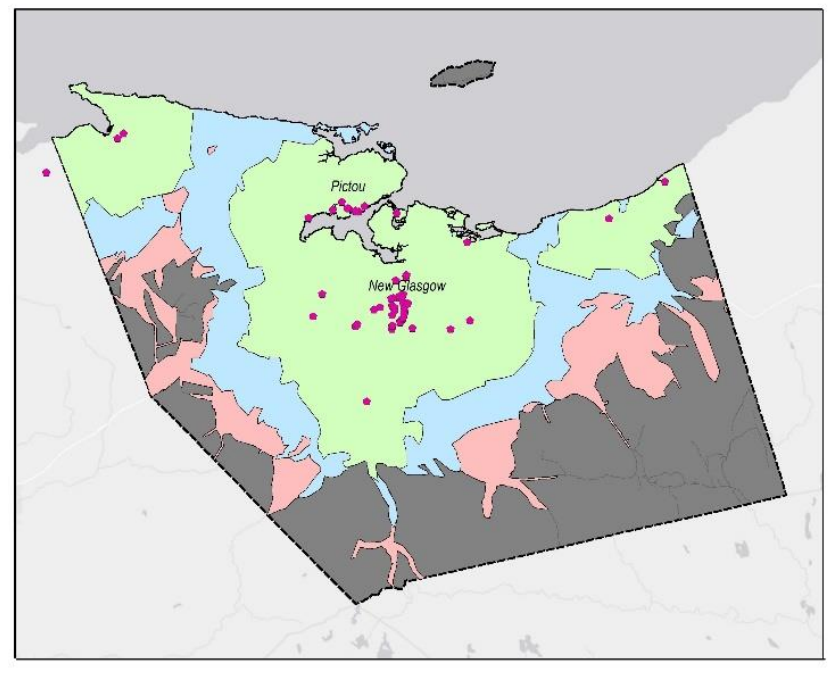

Legend

- Store Location

Roads

Pictou County

\$20 Taxi Ride From Outlet

$\$ 30$ Taxi Ride From Outlet

\$50 Taxi Ride From Outlet

\section{Taxi Ride Distances From Supermarkets}

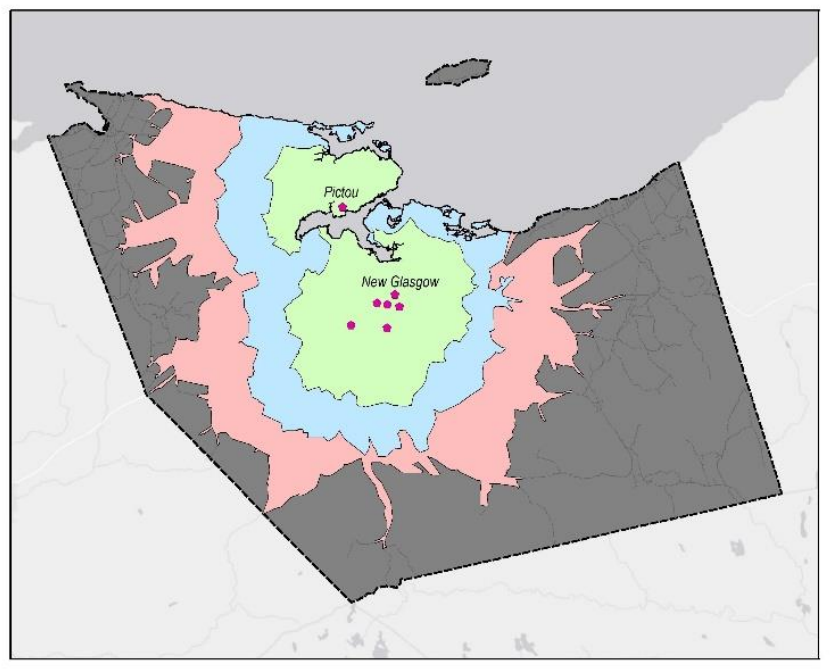

The lack of regular public transit services in these three rural communities means that residents often rely on taxi services, unless they have family or friends that they can ask to drive them to stores as needed. Residents outside of a \$20 taxi fare range must often spend more than \$40 to go to a food outlet and back if they do not have a car and cannot ask family or friends to drive them. 
Figure 6 (Maps 4a and 4b) shows a comparison of the areas covered by $\$ 20, \$ 30$ and $\$ 50$ taxi rides (one-way) in Pictou, where Map 4a includes all food outlets, and Map 4b includes only supermarkets. With the exception of Spryfield, at least some proportion of the residents of each community are outside of the areas in which a food outlet can be reached via a $\$ 20$ taxi ride (one-way). The proportions of each population outside of the three taxi fee ranges vary across the case communities (Table 4), although the populations in areas outside of a $\$ 30$ or $\$ 50$ taxi ride range are relatively small in all four communities. Over one third of the population of Eastern Shelburne County was outside of a \$20 taxi ride range of any food outlets, and nearly two thirds were outside of a $\$ 20$ range from supermarkets specifically. Kings County Northeast has a very small proportion of the population outside of a $\$ 20$ taxi ride range, as the majority of the population lives in or around the town centre.

Table 4: Comparison of the proportions of each population outside of $\$ 20, \$ 30$, and $\$ 50$ taxi ride range from all types of food outlets and from supermarkets

\begin{tabular}{|c|c|c|c|c|c|c|c|}
\hline & \multirow[b]{2}{*}{$\begin{array}{l}\text { Total population } \\
\text { size }\end{array}$} & \multicolumn{3}{|c|}{$\begin{array}{l}\text { Population outside of coverage by } \\
\text { all food outlets }\end{array}$} & \multicolumn{3}{|c|}{$\begin{array}{l}\text { Population outside of coverage by } \\
\text { supermarkets }\end{array}$} \\
\hline & & $\begin{array}{l}\text { Outside } \\
\$ 20 \\
\text { range }\end{array}$ & $\begin{array}{l}\text { Outside } \\
\$ 30 \\
\text { range }\end{array}$ & $\begin{array}{l}\text { Outside } \\
\$ 50 \\
\text { range }\end{array}$ & $\begin{array}{l}\text { Outside } \\
\$ 20 \text { range }\end{array}$ & $\begin{array}{l}\text { Outside } \\
\$ 30 \text { range }\end{array}$ & $\begin{array}{l}\text { Outside } \$ 50 \\
\text { range }\end{array}$ \\
\hline Eastern & 6,700 & & & & & & \\
\hline Shelburne & & & & & $62.2 \%$ & $48.8 \%$ & $24.8 \%$ \\
\hline County & & $36.2 \%$ & $13.7 \%$ & $4.4 \%$ & $(25.9+\%)$ & $(+35.0 \%)$ & $(+20.4 \%)$ \\
\hline Kings County & 33,720 & & & & $8.9 \%$ & $2.0 \%$ & $0.0 \%$ \\
\hline Northeast & & $3.9 \%$ & $1.0 \%$ & $0.0 \%$ & $(+5.0 \%)$ & $(+1.0 \%)$ & $(+0.0 \%)$ \\
\hline \multirow[t]{2}{*}{ Pictou } & 45,640 & & & & $34.0 \%$ & $18.3 \%$ & $9.3 \%$ \\
\hline & & $12.3 \%$ & $4.0 \%$ & $1.6 \%$ & $(+21.7 \%)$ & $(+14.2 \%)$ & $(+7.7 \%)$ \\
\hline Spryfield & 14,000 & $0 \%$ & $0 \%$ & $0 \%$ & $0 \%$ & $0 \%$ & $0 \%$ \\
\hline
\end{tabular}

Note: calculations are based on fee by distance (Casino Taxi, 2019), where a $\$ 20$ fare is equivalent to approximately $10 \mathrm{~km}$ (including the start cost), or about a 10- to 11-minute drive, assuming an average speed of 50 to $60 \mathrm{~km}$ per hour. This means that a $\$ 30$ fare will be about a $15 \mathrm{~km}$ drive, and $\$ 50$ will be a $28 \mathrm{~km}$ drive.

\section{Discussion}

This paper aimed to uncover a more realistic depiction of the extent of populations at risk of food insecurity in four Nova Scotia communities by incorporating qualitative insights from 
Photovoice data into GIS-based spatial analysis. While individual and family income is one of the most prominent risk factors for food insecurity, challenges in accessing food due to various physical environmental barriers may exacerbate the risk of not being able to obtain sufficient, affordable, and healthy food for individuals and families with low economic means. Our case communities - and likely others in the province - are faced with a myriad of physical barriers that are often not taken into account in the evaluation of accessibility of food outlets. Unsurprisingly, once some of these barriers were incorporated into our spatial analysis, a considerably higher proportion of residents were found to be outside of areas considered to have access to food outlets that are more affordable and provide a comprehensive selection of food items. Residents who live outside of the coverage areas and are in a socioeconomically precarious position are likely to be at a higher risk of food insecurity.

We focused on qualitative narratives from the perspectives of individuals who rely on public transit or walking to access food. With the exception of Spryfield, the case communities studied do not have regular public transit services. While some community-based transportation services exist, they are typically used for transporting the elderly to medical appointments, and do not run frequently enough for routine grocery shopping for many residents in need. While some Photovoice participants mentioned that they would sometimes ask friends and relatives to drive them, reluctance in asking for favours on a routine basis was reflected in one participant's comment: "when you're relying on the kindness of strangers or family members to take you grocery shopping you also don't feel like bringing home bags upon bags of things either" (Community Member, Photovoice). Car-share programs are not yet commonplace. Therefore, walking is likely the main (or even only) transportation option for many. Taxi rides are certainly not the most affordable, yet some residents resort to this option to avoid relying on their friends and neighbours.

\section{Limitations of the Study}

While we incorporated some key factors related to physical barriers to accessing food highlighted by the Photovoice participants, we were unable to assess many other factors due to lack of data. For example, participants pointed out that road (whether walking or driving) conditions in Nova Scotia in winter are particularly challenging. For four to five months of the year, icy roads and sidewalks make walking more difficult; people also must navigate rainy, windy, hot, or cold weather year-round. Participants also discussed how barriers related to navigating the built environment could be exacerbated for those with mobility challenges or with young children in a stroller. Data pertaining to snow clearance or general road maintenance were not available for all case communities. Although it was by no means our intention to incorporate a comprehensive list of factors mentioned by Photovoice participants, our investigation was limited by the availability of data that would have enabled more comprehensive investigation. 
Incorporating more factors in the analysis would likely reveal an even higher proportion of people without easy access to food.

The barriers felt by community members may also be exacerbated by some time-related factors. For example, having a bus stop nearby does not always mean that bus services are available throughout the day. Food outlets' hours of operation also vary, and uniform treatment of all outlets' hours of operation likely overestimates the availability of food services, which vary depending on day of the week and time of day. Typically, data that are available, including those used in this study, do not differentiate based on time-related factors, which also likely contributes to underestimation of the population at risk.

Our study focused on factors more easily addressed through alteration of the physical environment than those amenable to interventions in a social (welfare) realm. The removal of physical environmental barriers can help with the journey to access food, but this study does not address challenges associated with other individual and family life circumstances. As one community member commented: "(e)verything is accessible if you have a reliable vehicle and a healthy food budget” (Community Member, Photovoice). Thus, improving individuals' and families' economic conditions, alongside provision of affordable transportation, would be crucial to reducing the risk of food insecurity (ACT for CFS, 2015). In addition to difficulties caused by weather conditions and a lack of public transportation services, the Photovoice participants also expressed the need for childcare in order to access food due to the challenge of bringing children on grocery shopping and food bank trips, especially for lone parents (ACT for CFS, 2015).

Previously, the ACT for CFS study arrived at many policy recommendations related to improving community food security in the province of Nova Scotia (ACT for CFS, 2015). These included reviewing and changing by-laws related to transportation and incentivising businesses providing healthy and affordable food; investing in public transportation in rural communities; being creative with food provision methods such as grocery shuttle programs; and keeping the cost of food items down through bulk food programs (ACT for CFS, 2015). Our present findings add urgency to the need for implementing these recommended changes by showing the higher magnitude of potential risks related to a lack of food access faced by the population using this type of analysis compared to a simple density and proximity-based spatial analysis.

\section{Challenges of food access in Nova Scotia's rural and urban communities}

Clearly, a higher proportion of the population is outside of walking-distance based food service areas in rural communities. Besides the geographic sparseness of rural residents, market-driven allocation of food services is also inherently biased against less dense areas. A globalized food market characterized by "the trend toward monopsony and vertical integration of the food production and distribution system" (Van Hoesen et al., 2013, p. 2) has largely diminished the viability of small-scale neighbourhood food businesses, leaving many rural communities with only a few chain grocery stores, and meaning that residents must often travel long distances 
(Lebel et al., 2016; Sharkey, 2009; Smith et al., 2010). About 40\% of Nova Scotia's population lives in rural communities, which adds to the urgency of addressing built environmental barriers in the province. Recognizing the differences between the realities of food accessibility in urban and rural communities, including the presence or absence of large-scale, full-line grocery stores, small general stores, and farmers' markets, studies of food accessibility have started to characterize accessibility to different types of food outlets in rural communities (Bustillos et al., 2009; Lebel et al., 2016; Liese et al., 2007; Sharkey, 2009). However, there is still a limited volume of research articulating experiences related to the lack of physical accessibility of all types of food outlets in rural communities (Ball et al., 2006; Kirwan \& Maye, 2013; McEntee \& Agyeman, 2010; Rodriguez \& Grahame, 2016).

Although urban communities generally have better access to food outlets, they may also face physical barriers that are not captured by studies based solely on distance or food outlet density. Road slope or maintenance conditions, for instance, are not just rural issues. As demonstrated in the Spryfield context, a much higher proportion of the population may be outside of coverage areas once factors like road slope, poor road maintenance, or the need to walk on busy roads without sidewalks are taken into account. A recent study (Zhang \& Mao, 2019) found that disparities in spatial accessibility to food outlets between urban and rural communities were narrower when multiple modes of transportation (walking, biking, public transit, and driving) were incorporated in the spatial analysis than when only a single mode was considered. Neither these findings nor findings from our study suggest that rural and urban communities are equally disadvantaged. Rather, they suggest that more detailed investigations of the unique built and social environmental conditions in both rural and urban communities are necessary in order to better understand the challenges relevant to each of these contexts.

\section{Conclusion}

Much of current food-related policy research focuses on informing social policy and programs, targeting individuals and families that are at risk of food insecurity by alleviating some of the social and economic hardships they face. Our study looks at necessary changes in the built environment, demonstrating what specific infrastructural conditions - whether natural or anthropogenic - contribute to the proportion of the population facing challenges in accessing food. The study is still simplistic and limited to a narrow scope. Notwithstanding these limitations, our intention was not to incorporate an exhaustive list of potential physical barriers in the analysis, but rather to see how the extent of spatial access in the case communities changed once even a few key barriers were incorporated in the GIS analysis to determine spatial coverage of the population. Therefore, our study is exploratory in nature.

Often, in-depth qualitative narratives are considered 'soft' evidence which is difficult to translate into quantifiable measures. This study also represents an attempt to bridge the quantitative-qualitative methodological division (Warde, 2014) for food research. The additional 
value of our study is that we took one step further in showing the collaborative process of enhancing a spatial analysis of food access using community voices as critical attributes, without which the real extent of barriers to accessibility may be grossly underestimated.

\section{References}

ACT for CFS (2015). Making food matter: Strategies for activating change together - A participatory research report on community food security in Nova Scotia. Feed Nova Scotia. https://foodarc.ca/wp-content/uploads/2014/11/Making-Food-MatterReport_March2015rev.pdf

Allard, S. W., Wathen, M. V., Shaefer, H. L., \& Danziger, S. K. (2017). Neighborhood food infrastructure and food security in Metropolitan Detroit. The Journal of Consumer Affairs, 51(3), 556-597. https://www.doi.org/10.1111/joca.12153

Ball, K., Timperio, A. F., \& Crawford, D. A. (2006). Understanding environmental influences on nutrition and physical activity behaviors: Where should we look and what should we count? International Journal of Behavioral Nutrition and Physical Activity, 3(33), 1-8. https://doi.org/10.1186/1479-5868-3-33

Breyer, B., \& Voss-Andreae, A. (2013). Food mirages: Geographic and economic barriers to healthful food access in Portland, Oregon. Health \& Place, 24, 131-139. https://doi.org/10.1016/j.healthplace.2013.07.008

Bustillos, B., Sharkey, J. R., Anding, J., \& McIntosh, A. (2009). Availability of more healthful food alternatives in traditional, convenience, and non-traditional types of food stores in two rural Texas counties. Journal of the American Dietetic Association, 109(5), 883-889. https://doi.org/10.1016/j.jada.2009.02.011

Carter M.A., Dubois L., \& Tremblay M.S. (2014). Place and food insecurity: a critical review and synthesis of the literature. Public Health Nutrition. 17(1):94-112. https://doi.org/ $10.1017 / \mathrm{S} 1368980013000633$

Casino Taxi. (2019). Meter Rates - Administered by HRM. Casino Taxi. https://www.casinotaxi.ca/rates

Caspi, C., Kawachi, I., Subramanian, S. V., Adamkiewicz, G., \& Sorensen, G. (2012). The relationship between diet and perceived and objective access to supermarkets among lowincome housing residents. Social Science \& Medicine, 75(7), 1254-1262. https://doi.org/10.1016/j.socscimed.2012.05.014

Chen, X., \& Kwan, M. (2015). Contextual uncertainties, human mobility, and perceived food environment: The uncertain geographic context problem in food access research. American Journal of Public Health, 105(9), 1734-1737. https://doi.org/10.2105/AJPH.2015.302792

Cochrane, T., Yu, Y., Davey, R., Cerin, E., Cain, K. L., Conway, T. L., Kerr, J., Frank, L. D., Chapman, J. E., Adams, M. A., Macfarlane, D., Van Dyck, D., Lai, P-C., Sarmiento, O. L., Troelsen, J., Salvo, D., Reis, R., Mitáš, J., \& Sallis, J. F. (2019). Associations of built 
environment and proximity of food outlets with weight status: Analysis for 14 cities in 10 countries. Preventative Medicine, 129(105874), 1-13. http://hdl.handle.net/1854/LU8638628

Creswell, J. W. (2003). Research design: Qualitative, quantitative, and mixed methods approaches. Sage Publications Inc.

Dachner, N., \& Tarasuk, V. (2018). Tackling household food insecurity: An essential goal of a national food policy. Canadian Food Studies, 5(3), 230-247. https://doi.org/10.15353/cfsrcea.v5i3.278

Daganzo, C. F. (2010). Structure of competitive transit networks. Transportation Research Part B: Methodological, 44(4), 434-446. https://doi.org/10.1016/j.trb.2009.11.001

Dillahunt, T. R., \& Veinot, T. C. (2018). Getting there: Barriers and facilitators to transportation access in underserved communities. ACM Transactions on Computer-Human Interaction, 25(5), 29-39. https://doi.org/10.1145/3233985

Farmer, J. R., \& Minard, S. (2016). Local foods and low-income communities: Location, transportation, and values. Journal of Agriculture, Food Systems, and Community Development, 6(4), 41-53. https://doi.org/10.5304/jafscd.2016.064.009

Food and Agriculture Organization (2008). Food Security Information for Action: Practical Guides. http://www.fao.org

FoodARC. (2019). The Food Action Research Centre: Mission. http://foodarc.ca

Freedman, D. A. (2009). Local food environments: They're all stocked differently. American Journal of Community Psychology, 44(3-4), 382-393. https://doi.org/10.1007/s10464-009$\underline{9272-6}$

Glantz, K., Sallis, J. F., Saelens, B. E., \& Frank, L. D. (2005). Healthy nutrition environments: Concepts and measures. American Journal of Health Promotion, 19(5), 330-333. https://www.doi.org/10.4278/0890-1171-19.5.330

Guo, B. (2011). Household assets and food security: Evidence from the survey of program dynamics. Journal of Family Economic Issues, 32(1), 98-110. https://doi.org/10.1007/s10834-010-9194-3

Hillier, A., Cannuscio, C., Karpyn, A., McLaughlin, J., Chilton, M., \& Glanz, K. (2011). How far do low-income parents travel to shop for food? Empirical evidence from two urban neighbourhoods. Urban Geography, 32(5), 712-729. https://doi.org/10.2747/0272$\underline{3638.32 .5 .712}$

Horacek, T. M., Yildirim, E. D., Kelly, E., White, A. A., Shelnutt, K. P., Riggbee, K., Olfert, M. D., Morrell, J. S., Mathews, A. E., Mosby, T. T., Kidd, T., Kattelmann, K., Greene, G., Franzen-Castle, L., Colby, S., Byrd-Bredbenner, C., \& Brown, O. (2018). Development and validation of a simple convenience store SHELF audit. International Journal of Environmental Research and Public Health, 15(2676), 1-16. https://www.doi.org/10.3390/ijerph15122676 
Huang, J., Guo, B., \& Kim, Y. (2009). Food insecurity and disability: Do economic resources matter? Social Science Research, 39(1), 111-124. https://doi.org/10.1016/j.ssresearch.2009.07.002

Jilcott Pitts, S. B., Wu, Q., McGuirt, J., Crawford, T. W., Keyserling, T. C., \& Ammerman, A. S. (2013). Associations between access to farmers' markets and supermarkets, shopping patterns, fruit and vegetable consumption and health indicators among women of reproductive age in eastern North Carolina, USA. Public Health Nutrition, 16(11), 19441952. https://www.doi.org/10.1017/S1368980013001389.

Kirkpatrick, S., \& Tarasuk, V. (2010). Assessing the relevance of neighbourhood characteristics to the household food security of low-income Toronto families. Public Health Nutrition, 13(7), 1139-1148. https://doi.org/10.1017/S1368980010000339

Kirwan, J., \& Maye, D. (2013). Food security framings within the UK and the integration of local food systems. Journal of Rural Studies, 29, 91-100. https://doi.org/10.1016/j.jrurstud.2012.03.002

Kockelman, K., Zhao, Y., \& Blanchard-Zimmerman, C. (2001). Meeting the intent of ADA in sidewalk cross-slope design. Journal of Rehabilitation Research and Development, 38(1), 101-110. http://ezproxy.library.dal.ca/login?url=https://www-proquestcom.ezproxy.library.dal.ca/docview/70804064?accountid=10406

Larsen, K., Cook, B., Stone, M. R., \& Faulkner, G. E. J. (2015). Food access and children's BMI in Toronto, Ontario: Assessing how the food environment relates to overweight and obesity. International Journal of Public Health, 60(1), 69-77. https://doi.org/10.1007/s00038-014-0620-4

Larsen, K., \& Gilliland, J. (2006). Environmental equity and the grocery cart: Exploring urban 'food deserts.' Annual Meeting of the Association of American Geographers, March 7-11, Chicago, IL, USA.

Latz, A. (2017). Photovoice research in education and beyond: A practical guide from theory to exhibition. Routledge, Taylor \& Francis Group.

Lebel, A., Noreau, D., Tremblay, L., Oberle, C., Girard-Gadreau, M., Duguay, M., \& Block, J. (2016). Identifying rural food deserts: Methodological considerations for food environment interventions. Canadian Journal of Public Health, 107(S1), eS21-eS26. https://www.doi.org/ 10.17269/CJPH.107.5353

LeClair, M. S., \& Aksan, A-M. (2014). Redefining the food desert: Combining GIS with direct observation to measure food access. Agriculture and Human Values, 31(4), 537-547. https://doi.org/10.1007/s10460-014-9501-y

Liese, A. D., Weis, K. E., Pluto, D., Smith, E., \& Lawson, A. (2007). Food store types, availability, and cost of foods in a rural environment. Journal of the American Dietetic Association, 107(11), 1916-1923. https://doi.org/10.1016/j.jada.2007.08.012

Loopstra, R., \& Tarasuk, V. (2013). Severity of household food insecurity is sensitive to change in household income and employment status among low-income families. The Journal of Nutrition, 143(8), 1316-1323. https://www.doi.org/10.3945/jn.113.175414 
Ma, X., Sharpe, P. A., Bell, B. A., Liu, J., White, K., \& Liese, A. D. (2018). Food acquisition and shopping patterns among residents of low-income and low-access communities in South Carolina. Journal of the Academy of Nutrition and Dietetics, 118(10), 1844-1854. https://www.doi.org/10.3390/ijerph14091075

Macintyre, S. (2007). Deprivation amplification revisited; or, is it always true that poorer places have poorer access to resources for healthy diets and physical activity? International Journal of Behavioural Nutrition and Physical Activity, 4(1), 32. https://doi.org/10.1186/1479-5868-4-32

McEntee, J., \& Agyeman, J. (2010). Towards the development of a GIS method for identifying rural food deserts: Geographic access in Vermont, USA. Applied Geography, 30(1), 165176. https://doi.org/10.1016/j.apgeog.2009.05.004

McInerney, M., Csizmadi, I., Friedenreich, C. M., Alaniz Uribe, F., Nettel-Aguirre., A., McLaren, L., Potestio, M., Sandalack, B., \& McCormack, G. R. (2016). Associations between the neighbourhood food environment, neighbourhood socioeconomic status, and diet quality: An observational study. BMC Public Health, 16(984), 1-15. https://doi.org/10.1186/s12889-016-3631-7

McNamee, C., \& Rainham, D. (2014). ACT for CFS: Spatial analysis of food security risk in four Nova Scotian communities. http://foodarc.ca/actforcfs/

Meeder, M., Aebi, T., \& Weidmann, U. (2017). The influence of slope on walking activity and the pedestrian modal share. Transportation Research Procedia, 27, 141-147. https://doi.org/10.3929/ethz-b-000409249

Nykiforuk, C., Vallianatos, H., \& Nieuwendyk, L.M. (2011). Photovoice as a method for revealing community perceptions of the built and social environment. International Journal of Qualitative Methods, 10(2), 113-124. https://www.doi.org/10.1177/160940691101000201

Meener, M. R. (2019). Using participatory and mixed-methods approaches in GIS to develop a Place-Based Food Insecurity and Vulnerability Index. Environment and Planning A, 49(5), 1181-1205. https://www.doi.org/10.1177/0308518X16686352

Meza, A., Altman, E., Martinez, S., \& Leung, C. W. (2019). "It's a feeling that one is not worth food": A qualitative study exploring the psychosocial experience and academic consequences of food insecurity among college students. Journal of the Academy of Nutrition and Dietetics, 119(10), 1713-1721.

https://www.doi.org/10.1016/j.jand.2018.09.006

Nord, M., Andrews, M., \& Carlson, S. (2007). Household food security in the United States, 2006 (Economic Research Report 49). U.S. Department of Agriculture, Economic Research Service.

Nova Scotia Participatory Food Costing Project of the Nova Scotia Food Security Network. (2013). Pictures that represent voices... Examining impacts of participatory food costing on communities and organizations. http://foodarc.ca/wpcontent/uploads/2013/06/FC_Photovoice-Report_final_April-2013.pdf. 
Partington, S. N., Menzies, T. J., Colburn, T. A., Saelens, B. E., \& Glanz, K. (2015). Reduceditem food audits based on the nutrition environment measures surveys. American Journal of Preventative Medicine, 49(4), e23-e33. https://doi.org/10.1016/j.amepre.2015.04.036

Penchansky, R., \& Thomas, J. W. (1981) The concept of access: definition and relationship to consumer satisfaction. Medical Care. 19(2):127-40. https://www.jstor.org/stable/3764310

Rodriguez, R. M., \& Grahame, K. M. (2016). Understanding food access in a rural community: An ecological perspective. Food, Culture, and Society, 19(1), 171-194. https://doi.org/10.1080/15528014.2016.1145010

Saurman, E. (2016). Improving access: modifying Penchansky and Thomas's Theory of Access. Journal of Health Services Research \& Policy, 21(1), 36-39. https://doi.org/10.1177/1355819615600001

Shannon, J. (2016). Beyond the supermarket solution: Linking food deserts, neighbourhood context, and everyday mobility. Annals of the American Association of Geographers, 106(1), 186-202. https://doi.org/10.1080/00045608.2015.1095059

Sharkey, J.R. (2009). Measuring potential access to food stores and food-service places in rural areas in the U.S. American Journal of Preventative Medicine, 36(4), s151-s155. https://doi.org/10.1016/j.amepre.2009.01.004

Slater, J., Epp-Koop, S., Jakilazek, M., \& Green, C. (2017). Food deserts in Winnipeg, Canada: A novel method for measuring a complex and contested construct. Health Promotion and Chronic Disease Prevention in Canada, 37(10), 350-356. https://doi.org/10.24095/hpcdp.37.10.05

Smith, D. M., Cummins, S., Taylor, M., Dawson, J., Marshall, D., Sparks, L., \& Anderson, A. S. (2010). Neighbourhood food environment and area deprivation: Spatial accessibility to grocery stores selling fresh fruit and vegetables in urban and rural settings. International Journal of Epidemiology, 39(1), 277-284. https://doi.org/10.1093/ije/dyp221

Statistics Canada. (2011). Population, urban and rural by province and territory. Government of Canada. http://www.statcan.gc.ca/tables-tableaux/sum-som/101/ct01/demo62a-eng.htm

Tarasuk, V., Mitchell, A., \& Dachner, N. (2016). Household food insecurity in Canada, 2014. Toronto: Research to identify policy options to reduce food insecurity (PROOF). http://proof.utoronto.ca

Taxi Fares in Halifax, Canada. (2019). Numbeo. https://www.numbeo.com/taxi-fare/in/Halifax

Van der Velde, L. A., Schuilenburg, L. A., Thrivikraman, J. K., Numans, M. E., \& Kiefte-de Jong, J. C. (2019). Needs and perceptions regarding healthy eating among people at risk of food insecurity: A qualitative analysis. International Journal for Equity in Health, 18(184), 1-12. https://doi.org/10.1186/s12939-019-1077-0

Van Hoesen, J., Bunkley, B., \& Currier, C. (2013). A GIS-based methodology toward refining the concept of rural food deserts: A case study from Rutland County, Vermont. Journal of Agriculture, Food Systems, and Community Development, 3(2), 61-76. https://doi.org/10.5304/jafsed.2013.032.006. 
Warde, A. (2014). Food studies and the integration of multiple methods. Politica y Sociedad, 1, 51-72. https://doi.org/10.5209/rev_POSO.2014.v51.n1.42487

Widener, M. J. (2018). Spatial access to food: Retiring the food desert metaphor. Physiology \& Behaviour, 193, 257-260. https://doi.org/10.1016/j.physbeh.2018.02.032

Widener, M. J., Minaker, L. M., Reid, J. L., \& Patterson, Z. (2018). Activity space-based measures of the food environment and their relationships to food purchasing behaviours for young urban adults in Canada. Public Health Nutrition, 21(11), 2103-2116. https://doi.org/10.1017/S1368980018000435

Wrigley, N. (2002). "Food deserts" in British cities: Policy context and research priorities. Urban Studies, 39(11), 2029-2040. https://doi.org/10.1080/0042098022000011344

Zenk, S. N., Schulz, A. J., Israel, B. A., James, S. A., Bao, S., \& Wilson, M. L. (2005). Neighbourhood racial composition, neighbourhood poverty, and the spatial accessibility of supermarkets in Metropolitan Detroit. American Journal of Public Health, 95(4), 660-667. http://ezproxy.library.dal.ca/login?url=https://www-proquestcom.ezproxy.library.dal.ca/docview/215085691 ?accountid=10406

Zhang, J., \& Mao, L. (2019). Integrating multiple transportation modes into measures of spatial food accessibility. Journal of Transport and Health, 13, 1-11.

https://doi.org/10.1016/j.jth.2019.03.001 